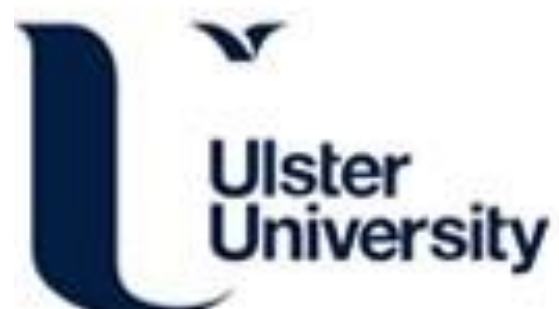

\section{Surface properties and sub-surface aggregate assimilation of rhamnolipid surfactants in different aqueous systems}

Raza, Z., Khalid, Z., Khan, M., Banat, I., \& et al, E. A. (2010). Surface properties and sub-surface aggregate assimilation of rhamnolipid surfactants in different aqueous systems. Biotechnology Letters, 32(6), 811-816.

Link to publication record in Ulster University Research Portal

Published in:

Biotechnology Letters

Publication Status:

Published (in print/issue): 01/06/2010

\section{Document Version}

Publisher's PDF, also known as Version of record

\section{General rights}

Copyright for the publications made accessible via Ulster University's Research Portal is retained by the author(s) and / or other copyright owners and it is a condition of accessing these publications that users recognise and abide by the legal requirements associated with these rights.

\section{Take down policy}

The Research Portal is Ulster University's institutional repository that provides access to Ulster's research outputs. Every effort has been made to ensure that content in the Research Portal does not infringe any person's rights, or applicable UK laws. If you discover content in the Research Portal that you believe breaches copyright or violates any law, please contact pure-support@ulster.ac.uk. 


\title{
Surface properties and sub-surface aggregate assimilation of rhamnolipid surfactants in different aqueous systems
}

\author{
Zulfiqar Ali Raza $\cdot$ Zafar M. Khalid • \\ Mohammad Saleem Khan • Ibrahim M. Banat • \\ Asma Rehman - Abdul Naeem - Muhammad Tahir Saddique
}

Received: 12 November 2009/Revised: 15 January 2010/ Accepted: 20 January 2010/Published online: 13 February 2010

(C) Springer Science+Business Media B.V. 2010

\begin{abstract}
Tensioactive properties of rhamnolipids produced by a Pseudomonas aeruginosa strain were investigated in the presence or absence of $\mathrm{Sr}^{2+}$ or $\mathrm{Pb}^{2+}$. Surface and interfacial properties, and aggregate forming properties and morphologies were studied by various techniques including scanning electron microscopy. When the $\mathrm{pH}$ of a rhamnolipid aqueous solution $(40 \mathrm{mg} / \mathrm{l})$ was increased from 5 to 8 , irregular vesicles gradually took the shape of oligo-vesicles, then regular vesicles and finally smaller spherical vesicles. Addition of metal ions controlled the aggregates' morphology and stability, and influenced the surface and interfacial behavior of rhamnolipid solutions.
\end{abstract}

\section{Z. A. Raza ( ()}

Department of Applied Sciences, National Textile University, Faisalabad 37610, Pakistan

e-mail: zarazapk@yahoo.com

\section{Z. M. Khalid · A. Rehman}

National Institute for Biotechnology and Genetic

Engineering, Faisalabad, Pakistan

\section{S. Khan - A. Naeem - M. T. Saddique}

National Centre of Excellence in Physical Chemistry,

University of Peshawar, Peshawar, Pakistan

I. M. Banat

School of Biomedical Sciences, University of Ulster, Coleraine BT52 1SA, Northern Ireland, UK
Keywords Aggregation - Biosurfactant . Pseudomonas aeruginosa $\cdot$ Rhamnolipid · Tensioactive

\section{Introduction}

The unique properties of glycolipid surfactants arise from the co-existence of both hydrophobic and hydrophilic moieties which often leads to the formation of highly organized microstructures by using intermolecular hydrogen bonding, hydrophobic and van der Waals interactions. The morphology of these microstructures depends on a number of factors including the relative fractions of different groups within the surfactant molecules, the shape of the surfactant molecules (Sanchez et al. 2007), the pH and the presence of metal ions in the surfactant solution (Champion et al. 1995).

Among various types of biosurfactants, much work has been carried out on microbial rhamnolipids (Arino et al. 1996; Deziel et al. 1999; Raza et al. 2007, 2009; Sim et al. 1997; Syldatk et al. 1985). More than 28 different congeners of rhamnolipids are produced by $P$. aeruginosa strains growing on different carbon sources (Deziel et al. 1999), most of them are di-rhamnolipids. These rhamnolipid molecules contain one or two $\beta$-hydroxy fatty acids of various chain length $\left(\mathrm{C}_{8}-\mathrm{C}_{22}\right)$ esters linked to a mono-rhamnose $(\mathrm{R})$ or di-rhamnose $(\mathrm{RR})$ moiety 
(Perfumo et al. 2006). Rhamnolipids have shown excellent efficiency in bacterial cell permeabilization (Sotirova et al. 2008), hydrocarbons solubilization and uptake (Ron and Rosenberg 2002), bioremediation (Rahman et al. 2003) and nanoparticles synthesis (Palanisamy 2008). These and many other applications of rhamnolipids are strongly affected by the addition of metal ions.

In the present study, two metal ions were selected; $\mathrm{Pb}^{2+}$ as a representative heavy metal contaminant commonly associated with health concerns and $\mathrm{Sr}^{2+}$ as one of the alkaline earth metals. Surface and aggregation behavior of rhamnolipids in solution at different ions concentration, $\mathrm{pH}$ values were investigated. Changes and presence of electrolytes of $\mathrm{SrCl}_{2} \cdot 6 \mathrm{H}_{2} \mathrm{O}$ or $\mathrm{Pb}\left(\mathrm{NO}_{3}\right)_{2}$ on the surface and interfacial behavior of rhamnolipids in the aqueous solutions were monitored, and the morphology and stability of the self-assembled rhamnolipid aggregates were observed using scanning electron microscopy.

\section{Materials and methods}

Materials

Rhamnolipids were produced by $P$. aeruginosa EBN8 mutant strain grown on canola oil refinery waste as previously described (Raza et al. 2007). The EBN-8 mutant was previously obtained through exposing cell suspension of $P$. aeruginosa S8 parent strain to gamma radiation dose of 400 Gy with 3 logarithms kill, plating on nutrient agar and incubating at $37^{\circ} \mathrm{C}$ (Iqbal et al. 1995). Rhamnolipids mixtures produced by this strain included $\mathrm{RC}_{10} \mathrm{C}_{10}(503 \mathrm{~m} / \mathrm{z}), \mathrm{RRC}_{10} \mathrm{C}_{8} /$ $\mathrm{RRC}_{8} \mathrm{C}_{10}$ (621), $\mathrm{RRC}_{10} \mathrm{C}_{10}$ (649) and $\mathrm{RRC}_{12} \mathrm{C}_{10}$ l $\mathrm{RRC}_{10} \mathrm{C}_{12}$ (677) all of which were analyzed as described by Raza et al. (2009).

Tensioactive measurements

Rhamnolipid solutions of different concentrations were prepared by direct dissolution into deionized water in the presence or absence of electrolyte $\left(\mathrm{Pb}^{2+}\right.$ or $\mathrm{Sr}^{2+}$ ). Rhamnolipid solutions were adjusted to between pH 5-8 using $0.1 \mathrm{M} \mathrm{NaOH}$ or $0.1 \mathrm{M} \mathrm{HCl}$. The solutions were filtered twice through a $0.45 \mu \mathrm{m}$ pore size nylon filter, and allowed the filtrate to equilibrate overnight in sealed test tubes at $25 \pm 2^{\circ} \mathrm{C}$.
Surface tension and interfacial tension (IFT) of rhamnolipid solution versus hexadecane were measured using a digital de Noüy ring tensiometer (K10T, Krüss, Germany), and the CMC of the rhamnolipid surfactant in the aqueous medium was determined from the break point of the surface tension versus rhamnolipid concentration curve. The results reported are average of three parallel sets of experiments.

Rhamnolipid thin film preparation for SEM investigation

Thin films were prepared by placing separate rhamnolipid solutions $(5 \mu \mathrm{l})$ up to $100 \mathrm{mg} / \mathrm{l}$ under various $\mathrm{pH}$ and metal ion concentrations onto glass slides coated with a film of Formvar/ethylene dichloride/ glycerol solution. The aqueous layers were allowed to equilibrate and self-assemble the rhamnolipid aggregates for $24 \mathrm{~h}$ at $25 \pm 2{ }^{\circ} \mathrm{C}$, and subsequently dried by removing the solvent under a stream of $\mathrm{N}_{2}$ gas followed by evacuation to $50 \mu \mathrm{m} \mathrm{Hg}$ for overnight.

Scanning electron microscopy

Electronic images of the dried thin film of rhamnolipid self-assemblies were scanned using an SEM (JSM-5910, JEOL, Japan). The film was underexposed at a setting of $5 \mathrm{kV}$ and overdeveloped for $10 \mathrm{~min}$ to enhance the contrast.

\section{Results and discussion}

Surface and subsurface behavior

Rhamnolipids' hydrophilicity is due to rhamnosyl groups, whereas the carboxylic moieties confers the amphipathic characteristics depending on the subphase conditions such as $\mathrm{pH}$ and electrolytic strength. The amphipathic behavior of rhamnolipid was evaluated at different concentrations in the presence or absence of separate electrolytes of $\mathrm{SrCl}_{2} \cdot 6 \mathrm{H}_{2} \mathrm{O}$ and $\mathrm{Pb}\left(\mathrm{NO}_{3}\right)_{2}$, and in the $\mathrm{pH}$ range of 5 to 8 (Figs. 1, 2). The rhamnolipid profiles in the pre-saturation region $(0-10 \mathrm{mg} / \mathrm{l})$ practically remained parallel to the concentration axis. At higher concentrations, rhamnolipid molecules travelled into the air/liquid interface to saturate it, resulting in significant reduction in the surface tension (Fig. 1). 

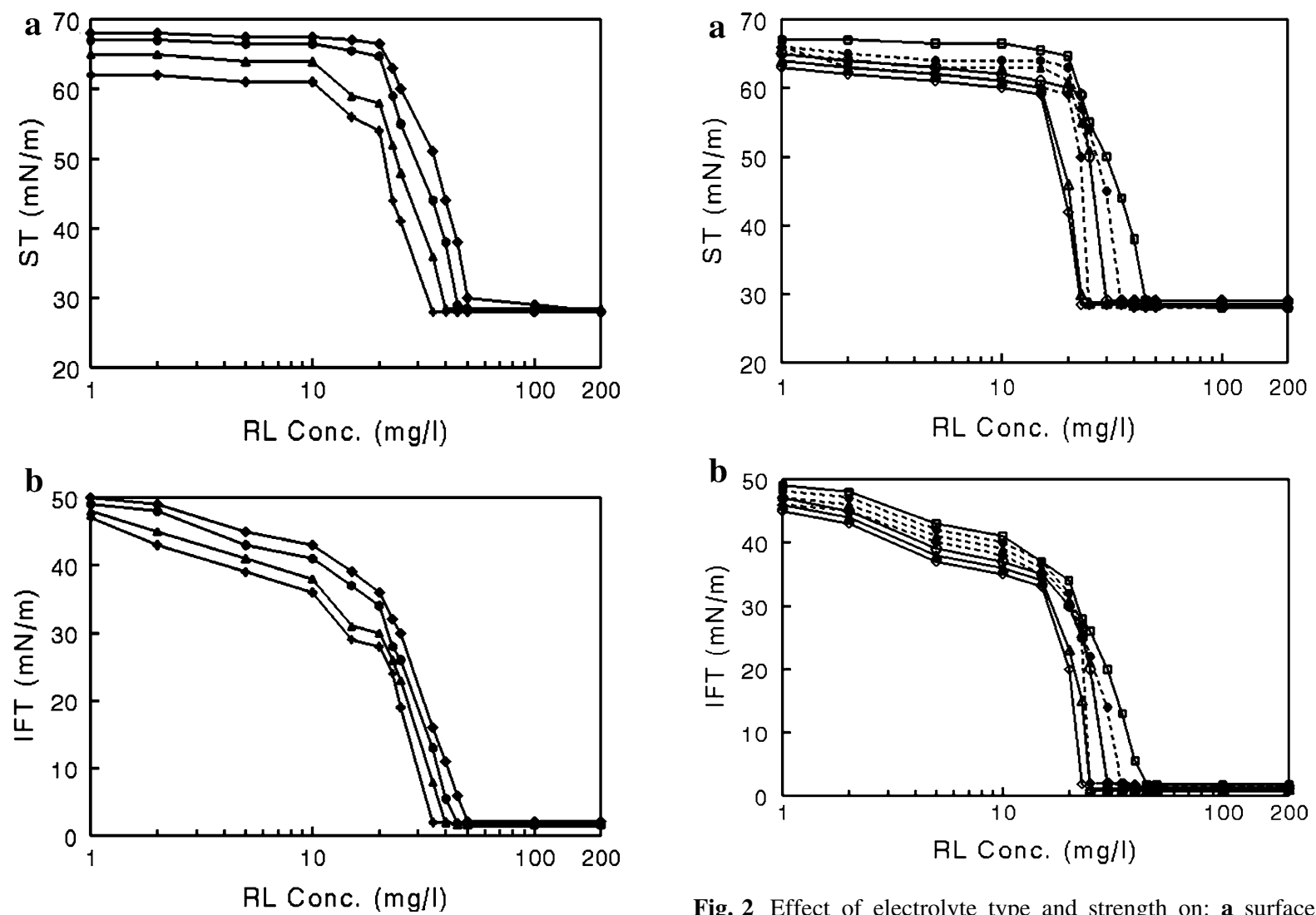

Fig. 1 Effect of $\mathrm{pH}$ on: a surface tension, CMC, and; b interfacial tension of rhamnolipids in the aqueous media. (Plus) $\mathrm{pH} 5$; (filled triangles) $\mathrm{pH}$ 6; (filled circles) $\mathrm{pH} 7$; (filled diamonds) $\mathrm{pH} 8$

At $\mathrm{pH} 5$ or 6, the surface and interfacial tensions of aqueous solution decreased but not uniformly with rhamnolipid concentration particularly at the beginning of inclined region (10-20 mg/l) (Fig. 1). This irregular decline was different from that observed at either $\mathrm{pH}$ value when the rhamnolipids concentration reached the CMC (at 35-50 mg/l). This first decline at the biosurfactant concentration of $10 \mathrm{mg} / \mathrm{l}$ is attributed to the micellization of dirhamnolipid because this value resembles the CMC of dirhamnolipids reported elsewhere (Syldatk et al. 1985), while the second decline, at $40 \mathrm{mg}$ rhamnolipids/l, is closer to the CMC of the rhamnolipids mixture (Ishigami et al. 1993; Raza et al. 2009).

The carboxyl group of the rhamnolipid molecule is $\mathrm{pH}$ sensitive; at $>\mathrm{pH} 5$, it dissociates to its conjugate base i.e. carboxylate anion whereas at $\leq \mathrm{pH} 5$, it is almost totally protonated and exhibits nonionic

behavior in the aqueous solutions (Ishigami et al. 1993). Upon increasing the $\mathrm{pH}$ from 5 to 8 , the CMC of (nonionic state) rhamnolipids increased from 35 to over $50 \mathrm{mg} / \mathrm{l}$ and the respective (surface tension) $\sigma_{\mathrm{CMC}}$ values were 28.2 and $30.1 \mathrm{mN} / \mathrm{m}$. Thus the $\mathrm{CMC}$ of more negatively charged rhamnolipid having more intermolecular repulsive force is higher than that of the less negatively charged (or neutral) rhamnolipid molecules (Fig. 1a). As the $\mathrm{pH}$ of the surfactant solution decreases, the carboxyl group in the rhamnolipid head group becomes more protonated, thereby reducing the repulsion between the head groups, and allowing a closer packing of rhamnolipid molecules at the interface, which results in higher surfactant concentration at the interface, hence reducing the IFT (Fig. 1b).

The performance and solubilization capacity of anionic state rhamnolipid surfactants are influenced 
both qualitatively and quantitatively by the presence or absence of electrolytes in the aqueous solution. The addition of $\mathrm{Pb}^{2+} / \mathrm{Sr}^{2+}$ ions into the rhamnolipid solutions lowered the surface tension and CMC values. This may be attributed to the ability of the cations in the solution phase to shield the carboxylate groups of the rhamnolipid molecules causing them to behave more like nonionic surfactants, as displayed by the change in the shapes of surface tension profiles (Fig. 2a). Here, the steep slope in the rate of surface tension reduction before the CMC of rhamnolipids indicates the compaction of rhamnolipid molecules, which accelerates the reduction of surface tension and the CMC values.
The change in electrolytic concentration apparently changes the partitioning of the biosurfactant amount between the two immiscible phases. In the aqueous phase, the anionic rhamnolipid forms a complex with the cations and becomes more nonionic. This decreases its affinity to aqueous phase and leaves it free to either remain in the aqueous phase or approach the oil phase. When the rhamnolipid concentration is roughly balanced between the two phases, then the IFT value is expected to reach minimum possible (Fig. 2b). More trends of changing the $\mathrm{CMC}, \sigma_{\mathrm{CMC}}$ and $\gamma_{\mathrm{CMC}}$ values at various electrolyte concentrations can be observed in the data given in Table 1.

Table 1 Effect of ionic strength on the critical micelle concentration (CMC), surface tension at CMC $\left(\sigma_{\mathrm{cmc}}\right)$ and interfacial tension at $\mathrm{CMC}\left(\gamma_{\mathrm{cmc}}\right)$ at $\mathrm{pH} 7$

\begin{tabular}{|c|c|c|c|c|c|c|}
\hline \multirow{2}{*}{$\begin{array}{l}\text { Electrolyte } \\
\text { concentration }(\mathrm{mM})\end{array}$} & \multicolumn{2}{|c|}{ CMC (mg/l) } & \multicolumn{2}{|c|}{$\sigma_{\mathrm{CMC}}(\mathrm{mN} / \mathrm{m})$} & \multicolumn{2}{|c|}{$\gamma_{\mathrm{CMC}}(\mathrm{mN} / \mathrm{m})$} \\
\hline & $\mathrm{Sr}^{2+}$ & $\mathrm{Pb}^{2+}$ & $\mathrm{Sr}^{2+}$ & $\mathrm{Pb}^{2+}$ & $\mathrm{Sr}^{2+}$ & $\mathrm{Pb}^{2+}$ \\
\hline 0 & 45 & 45 & 29 & 29 & 1.8 & 1.8 \\
\hline 0.5 & 35 & 30 & 29 & 29 & 1.4 & 1.3 \\
\hline 1 & 30 & 25 & 29 & 29 & 1.3 & 1.1 \\
\hline 2 & 25 & 23 & 28 & 28 & 1.2 & 0.9 \\
\hline
\end{tabular}

Fig. 3 SEM of selfassembled rhamnolipids $(40 \mathrm{mg} / \mathrm{l})$ thin film fabricated on a glass surface at $\mathrm{pH}$ : a 5; b 6; c 7; d 8 with respective insets at higher magnification
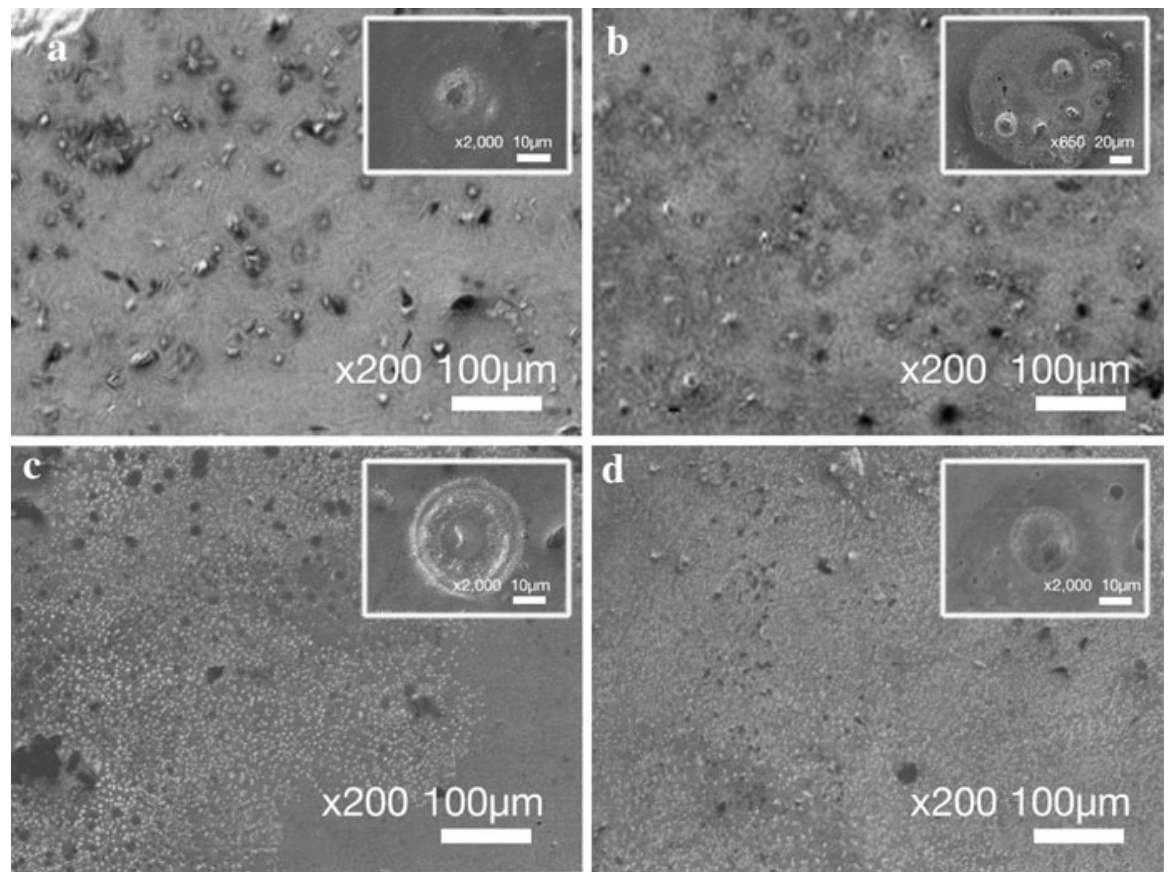
Structural features

The CMC of dirhamnolipids having two rhamnose moieties has been reported to be slightly higher than that of monorhamnolipid (Champion et al. 1995; Ishigami et al. 1993); in the present study, the CMC of rhamnolipids mix was higher than that of the isolate dirhamnolipids, which may be due to: (i) high hydrophobic character of mixed rhamnolipids molecules, (ii) rhamnolipids mixture contains different congeners; all of which may be involved in micellization. Instauration of any of the components could affect the conformation of molecules in the micelles, thus increasing the CMC. However, rhamnolipid molecules added to the aqueous solution, at post-CMC, does rupture or not over-saturate the surfactant monolayer formed at the air/liquid interface; instead they may affect the size and structure of micelle aggregates in the subsurface.

Being composed of different lengths of hydroxy fatty acids, rhamnolipid moieties have a wide range of distribution, which might be responsible for the coexistence of morphologically different aggregates (Figs. 3, 4). The rhamnolipid morphology has been observed as a function of $\mathrm{pH}$. On increasing the $\mathrm{pH}$ of rhamnolipid solution (of $40 \mathrm{mg} / \mathrm{l}$ ) from 5 to 8 , the irregular vesicles gradually changed shape to oligovesicles, then regular vesicles and finally smaller spherical vesicles (insets of Fig. 3). The increase in the $\mathrm{pH}$ of solution could enhance negative charge on the hydrophilic moiety of rhamnolipid, so the repulsive forces between the adjacent hydrophilic head groups of rhamnolipids increase, leading to a larger head diameter which doesn't support the formation of large spherical vesicles.

At $\mathrm{pH} 6$ (and pH 5) with $60 \mathrm{mg}$ rhamnolipid/l, star-like microstructures were observed (Fig. 4a). At $\mathrm{pH} 7$ or 8 and with $40 \mathrm{mg} / \mathrm{l}$, regular vesicular dispersions were observed (Fig. 3c, d), which collapsed at higher rhamnolipid concentration of $100 \mathrm{mg} / \mathrm{l}$ (Fig. 3d). At a specific pH value, a structural variation was observed in the vesicular dispersion on increasing the concentration of rhamnolipids. For example at $\mathrm{pH} 7$, the regular vesicles were shifted to oligo- then to cylindrical- and finally to burstvesicles as the rhamnolipids concentration increased from 20 to $100 \mathrm{mg} / \mathrm{l}$ (Figs. 3c, 4b).

The addition of $\mathrm{Sr}^{2+} / \mathrm{Pb}^{2+}$ into rhamnolipid solution might regulate micelles formation due to electrostatic bonding between $\mathrm{Sr}^{2+}$ and the negatively
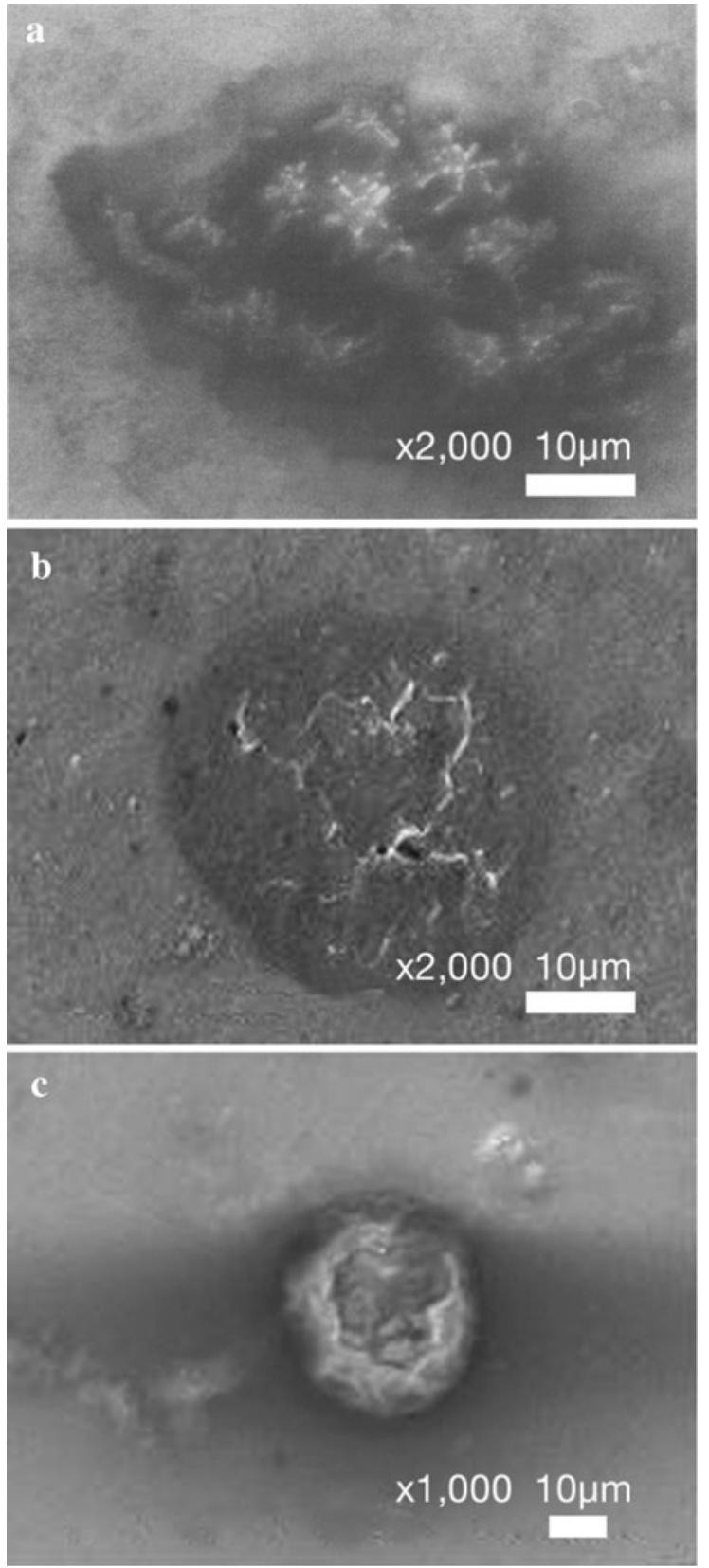

Fig. 4 SEM of self-assembled rhamnolipids (RLs) thin film fabricated on a glass surface at: a $60 \mathrm{mg} \mathrm{RLs} / \mathrm{l}, \mathrm{pH}$ 6; b $100 \mathrm{mg}$ RLs/l, pH 7; c 100 mg RLs/l, pH 7, 2 mM PbNO

charged carboxylate group; or the chelating activity via a bidentate ligand in the case of $\mathrm{Pb}^{2+}$. The addition of lead ions to rhamnolipids solution of $100 \mathrm{mg} / \mathrm{l}$ gave a slight stability to bust vesicles, which rearranged their shapes to oligo-spherical vesicles at $2 \mathrm{mM} \mathrm{Pb}^{2+}$ (Fig. 4c). 


\section{Conclusions}

Control of ionic strength and $\mathrm{pH}$ in aqueous solution is an important factor to be considered in rhamnolipids application including surfactant-enhanced subsurface remediation. These factors also affect self-aggregation of rhamnolipids in the aqueous media that formed diverse microstructures, which may find valuable applications in enhanced oil recovery, detergency, nanotechnology, microreactors, biocatalysis and drug delivery among many other applications.

Acknowledgment The authors acknowledge Director, Centralized Resource Laboratory, University of Peshawar for the SEM facility.

\section{References}

Arino S, Marchal R, Vandecasteele JP (1996) Identification and production of a rhamnolipidic biosurfactant by a Pseudomonas species. Appl Microbiol Biotechnol 45: $162-168$

Champion JT, Gilkey JC, Lamparski H et al (1995) Electron microscopy of rhamnolipid (biosurfactant) morphology: effects of $\mathrm{pH}$, cadmium, and octadecane. J Colloid Interface Sci 170:569-574

Deziel EF, Lepine F, Dennie D et al (1999) Liquid chromatography/mass spectrometry analysis of mixtures of rhamnolipids produced by Pseudomonas aeruginosa strain 57RP grown on mannitol or naphthalene. Biochim Biophys Acta 1440:244-252

Iqbal S, Khalid ZM, Malik KA (1995) Enhanced biodegradation and emulsification of crude oil and hyperproduction of biosurfactants by a gamma ray-induced mutant of Pseudomonas aeruginosa. Lett Appl Microbiol 21:176-179
Ishigami Y, Gama Y, Fumiyoshi I et al (1993) Colloid chemical effect of polar head moieties of a rhamnolipidtype biosurfactant. Langmuir 9:1634-1636

Palanisamy P (2008) Biosurfactant mediated synthesis of $\mathrm{NiO}$ nanorods. Mater Lett 62:743-746

Perfumo A, Banat IM, Canganella R et al (2006) Rhamnolipid production by a novel thermotolerant hydrocarbondegrading Pseudomonas aeruginosa AP02-1. J Appl Microbiol Biotechnol 72:132-138

Rahman KSM, Rahman TJ, Kourkoutas Y et al (2003) Enhanced bioremediation of n-alkane in petroleum sludge using bacterial consortium amended with rhamnolipid and micronutrients. Bioresour Technol 90:159-168

Raza ZA, Rehman A, Khan MS et al (2007) Improved production of biosurfactant by a Pseudomonas aeruginosa mutant using vegetable oil refinery wastes. Biodegradation 18:115-121

Raza ZA, Khalid ZM, Banat IM (2009) Characterization of rhamnolipids produced by a Pseudomonas aeruginosa mutant strain grown on waste oils. J Environ Sci Health A44:1367-1373

Ron EZ, Rosenberg E (2002) Biosurfactants and oil bioremediation. Curr Opin Biotechnol 13:249-252

Sanchez M, Aranda FJ, Espuny MJ et al (2007) Aggregation behaviour of a dirhamnolipid biosurfactant secreted by Pseudomonas aeruginosa in aqueous media. J Colloid Interface Sci 307:246-253

Sim L, Ward OP, Li ZY (1997) Production and characterization of a biosurfactant isolated from Pseudomonas aeruginosa UW-1. J Ind Microbiol Biotechnol 19:232-238

Sotirova AV, Spasova DI, Galabova DN et al (2008) Rhamnolipid-biosurfactant permeabilizing on Gram-positive and Gram-negative bacterial strains. Curr Microbiol 56: 639-644

Syldatk C, Lang S, Matulovic U et al (1985) Production of four interfacial active rhamnolipids from $n$-alkanes or glycerol by resting cells of Pseudomonas species DSM 2874. Z Naturforsch 40c:61-67 